\title{
High incidence of venous thrombosis in patients with moderate-to-severe COVID-19
}

\author{
Oleg Kerbikov $^{1}$ (i) $\cdot$ Pavel Orekhov $^{1} \cdot$ Ekaterina Borskaya $^{2} \cdot$ Natalia Nosenko $^{1}$
}

Received: 22 July 2020 / Revised: 3 December 2020 / Accepted: 7 December 2020 / Published online: 3 January 2021

(c) Japanese Society of Hematology 2021

\begin{abstract}
Increasing evidence suggests that COVID-19 may be associated with venous thromboembolism, and much data exists regarding high incidence of venous thrombosis in critical COVID-19 patients. However, evidence on this complication in less severe patients is not widely available. The aim of this study was to investigate the incidence of deep-vein thrombosis (DVT) in patients with moderate-to-severe COVID-19, to assess the prevalence of DVT with duplex ultrasound, and to compare patients with DVT and those without it using lung computerized tomography (CT), clinical information and lab data. The subjects of this study were 75 consecutive patients (aged 27-92 y, median-63 y; 36 males and 39 females) with moderateto-severe COVID-19. DVT was found in 15 patients (20\%). The vast majority of those with DVT (13 patients, $86.7 \%$ ) had thrombi in calf veins and 2 (13.3\%) had ileofemoral thrombosis. High incidence of DVT (20\%) is observed even in patients with moderate-to-severe COVID-19. These patients require early anticoagulation therapy as part of their treatment. Such therapy may be continued after hospital discharge and these patients may also require follow-up vein ultrasonography after recovery to rule out DVT.
\end{abstract}

Keywords COVID-19 · Venous thrombosis · Anticoagulants · Thrombosis

\section{Introduction}

Several studies revealed high incidence of venous thromboembolic complications (VTE) in patients with severe and critical COVID-19 [1-3]. Wichmann et al. [1] found venous thrombosis in seven out of 12 consecutive autopsies of patients with COVID-19, while Nahum J et al. found deep-vein thrombosis (DVT) in $65 \%$ of patients (22 out of 34 ) admitted to ICU (ultrasonography exam was performed at admission) [2].

In contrast, there is not enough data about frequency of DVT in patients with less severe form of disease. The aim of this study was to evaluate incidence of DVT in patients with moderate-to-severe COVID-19 and to assess the possible connection of DVT with clinical findings lung CT scores and laboratory data.

Oleg Kerbikov

o.kerbikov@gmail.com

1 Federal State Research Clinical Center, FMBA of Russia, Orekhovy bld 28, 115682 Moscow, Russia

2 Burnasyan Federal Medical Biophysical Center FMBA of Russia, Moscow, Russia

\section{Methods}

Almost all patients admitted to Federal State Clinical Research Hospital FMBA of Russia with confirmed COVID-19 in the first half of May 2020 underwent venous duplex ultrasonography exam within 7 days following hospital admission. Critical patients who required admission to ICU, patients with more than $75 \%$ of lungs affected (as evidenced by lung CT exam), patients with a known history of DVT and patients with recent leg and hip trauma were excluded from analysis. A total of 75 consecutive patients (pts) (Table 1) with moderate-to-severe COVID-19 were included in our study.

\section{Results}

Vein ultrasonography revealed spontaneous echo contrast in common femoral veins in 53 pts $(70.7 \%)$ which indicated blood stasis and markedly decreased venous flow velocity in majority of patients. DVT was found in $15 \mathrm{pts}$ $(20 \%)$. A majority of patients were found to have thrombi in calf veins only (13 pts, $86.7 \%)$ and 2 pts (13.3\%) have 
Table 1 Patient characteristics (75 Patients)

\begin{tabular}{|c|c|}
\hline Age & $\begin{array}{l}\text { 27-92 y } \\
\text { Median } 63 \text { y, Mean } 63.41 \text { y }\end{array}$ \\
\hline Gender & 36 males, 39 females \\
\hline COVID-19 complications & $\begin{array}{l}\text { Bilateral pneumonia } 74 \text { pts }(98.7 \%) \text {, Unilateral pneu- } \\
\text { monia } 1 \text { pts }(1.3 \%)\end{array}$ \\
\hline \multicolumn{2}{|l|}{ Underlying concomitant diseases and conditions } \\
\hline Diabetes mellitus & 12 pts $(16 \%)$ \\
\hline Oncology & 8 pts $(10.7 \%)$ \\
\hline Arterial hypertension & 36 pts $(48 \%)$ \\
\hline Ischemic heart disease & 19 pts $(26.4 \%)$ \\
\hline Atrial fibrillation (paroxysmal) & 5 pts $(6.7 \%)$ \\
\hline Chronic lung diseases & 9 pts $(12 \%)$ \\
\hline Obesity & 4 pts $(5.3 \%)$ \\
\hline Days from symptoms onset to admission & $1-43$ days, Median -8 days, Mean-8.95 days \\
\hline $\mathrm{SpaO} 2$ at admission & 80-99\%, Median—95\%, Mean-93.7\% \\
\hline \multicolumn{2}{|l|}{ Lung CT scores at admission (according to G. Huang et al. [4]*) } \\
\hline 1 & $2(2.7 \%)$ \\
\hline 2 & $6(8 \%)$ \\
\hline 3 & $39(52 \%)$ \\
\hline 4 & $28(37.3 \%)$ \\
\hline Oxygen therapy at some point (low-flow oxygen $2-12 \mathrm{~L} / \mathrm{min}$ ) & 59 pts $(79 \%)$ \\
\hline \multicolumn{2}{|l|}{ Lab data } \\
\hline APPT $\sec ^{* *}$ & 22-101, Mean-37.55 (reference values (RV) - 25-35) \\
\hline D-dimer, $\mathrm{mcg} / \mathrm{mL}$ & $0.09-5.0$, Mean $-0.75(\mathrm{RV}-0.02-0.5)$ \\
\hline Creatinine, $\mathrm{mcmol} / \mathrm{L}$ & 42.7-311, Mean-89.69 (RV—53-97) \\
\hline C-reactive protein, $\mathrm{mg} / \mathrm{L}$ & 1.4-385, Mean-75.33 (RV—> 10) \\
\hline Platelet count, $10^{\wedge} 9 / \mathrm{L}$ & 111-519 Mean-246.8 (RV-120-380) \\
\hline Blood glucose, $\mathrm{mmol} / \mathrm{L}$ & 2.1-15.27 Mean-6.7 (RV-3.9-6.4) \\
\hline
\end{tabular}

**0 denoted no involvement; 1 denoted less than 5\% involvement; 2 denoted 5-25\% involvement; 3 denoted 26-49\% involvement; 4 denoted $50-75 \%$ involvement; and 5 denoted more than $75 \%$ involvement

ileofemoral thrombosis. These same 2 pts have floating thrombi with a high risk of pulmonary embolism. Most of the thrombi $(64 \%)$ were occlusive thrombi in the peroneal, posterior tibial veins and sinuses. 4 pts $(26.7 \%)$ had bilateral DVT and 11 (73.3\%) unilateral. Also, in two patients we detected thrombi in upper extremities veins. No significant difference was observed between DVT and non-DVT patients with respect to age, underlying diseases, lung CT scores, $\mathrm{SpaO} 2$ at admission and the majority of lab data (Table 2).

However, a significant difference was observed in D-dimer level and C-reactive protein for patients with DVT and patients without DVT respectably. For D-dimer evaluation, we used quantitative, latex enhanced immunoturbidimetric immunoassay. Reference range for normal values was $<0.5 \mu \mathrm{g} / \mathrm{mL}$ Receiver operating characteristics (ROC) analysis revealed that the level of D-dimer $\geq 0.69 \mathrm{mcg} / \mathrm{mL}$ is the predictor of DVT (sensitivity $=76.9 \%$, specificity $=77.6 \%, p<0.001)$.

\section{Discussion}

In our study, we found relatively high (20\%) incidence of DVT in patients with moderate-to-severe COVID-19 and most of these patients have signs of decreased venous velocity and blood stasis. Follow the recommendations of the International Society on Thrombosis and Hemostasis (ISTH) [5] all patients admitted to our hospital with COVID19 (with the exception of those who have clear contraindications like active bleeding and platelet count less than $25 \times 109 / \mathrm{L}$ ) receive thromboprophylaxis with nadroparin calcium (dose 0.4-0.6 ml daily, administration 1-2 times a day. Each ml of aqueous solution contains 9500 anti-Xa IU of nadroparin calcium). In patients with DVT anticoagulant therapy was adjusted. However, despite intensive anticoagulant treatment the results were limited and all thrombi persisted, which is consistent with [2]. Two of patients had ileofemoral thromobosis with an accompanied high risk of pulmonary embolism, which was averted thanks 
Table 2 Comparison between patients with DVT (Group 1) and those without thrombi in the deep veins of the lower extremities (Group 2)

\begin{tabular}{|c|c|c|c|c|c|}
\hline & $\begin{array}{l}\text { Patients with DVT } \\
\text { (Group 1) } \\
15 \text { pts }\end{array}$ & $\begin{array}{l}\text { Patients without } \\
\text { DVT (Group 2) } \\
60 \text { pts }\end{array}$ & $\mathrm{p}$ & $\begin{array}{l}\text { Std. Dev.* } \\
\text { (Group 1) }\end{array}$ & $\begin{array}{l}\text { Std. Dev } \\
\text { (Group 2) }\end{array}$ \\
\hline Age (years) & 62 & 69.1 & 0.087 & 15.21 & 14.03 \\
\hline \multicolumn{6}{|l|}{ Underlying concomitant diseases and conditions } \\
\hline Diabetes mellitus (pts) & $2(13.3 \%)$ & $10(16.7 \%)$ & $0.753 * *$ & & \\
\hline Oncology (pts) & $1(6.7 \%)$ & $7(11.7 \%)$ & $0.575^{* *}$ & & \\
\hline Arterial hypertension (pts) & $10(66.7 \%)$ & $26(43.3 \%)$ & $0.106^{* *}$ & & \\
\hline Ischemic heart disease (pts) & $6(40 \%)$ & $13(21.7 \%)$ & $0.144 * *$ & & \\
\hline Atrial fibrillation (paroxysmal) (pts) & $2(13.3 \%)$ & $3(5 \%)$ & $0.259 * *$ & & \\
\hline Chronic lung diseases (pts) & $1(6.7 \%)$ & $8(13.3 \%)$ & $0.477 * *$ & & \\
\hline Time from symptoms onset to admission (days) & 11.2 & 8.4 & 0.153 & 9.71 & 5.59 \\
\hline $\mathrm{SpaO} 2$ at admission $(\%)$ & 94 & 92.6 & 0.192 & 3.9 & 3.5 \\
\hline Lung CT scores at admission & 3.4 & 3.2 & 0.335 & 0,63 & 0.73 \\
\hline APPT sec & 40.5 & 36.9 & 0.34 & 11.46 & 12.6 \\
\hline D-dimer, mcg/mL & 1.87 & 0.51 & $<0.0001$ & 1.62 & 0.4 \\
\hline Creatinine, $\mathrm{mcmol} / \mathrm{L}$ & 83.96 & 90.9 & 0.643 & 60.36 & 43.8 \\
\hline C-reactive protein, $\mathrm{mg} / \mathrm{L}$ & 116.9 & 65,1 & 0.014 & 83.6 & 64.98 \\
\hline Platelet count, $10^{\wedge} 9 / \mathrm{L}$ & 272.7 & 239.7 & 0.203 & 85.0 & 85.3 \\
\hline Blood glucose, $\mathrm{mmol} / \mathrm{L}$ & 6.0 & 6.9 & 0.185 & 1.3 & 2.3 \\
\hline
\end{tabular}

Bold value represents the significant difference between Group 1 and Group 2, $p<0.05$

*Std. Dev. standard deviation (where applicable)

**Calculated using Chi-square test

to early detection. Also, in two of patients with DVT, we detected thrombi in upper extremities veins which highlights the possibility of widespread thrombi formations in patients even with only moderate COVID-19. Clinical data have demonstrated that COVID-19 is associated with a significant risk of thrombotic complications ranging from microvascular thrombosis, venous thromboembolic disease, and stroke [6]. A number of reports described the issue of pulmonary thrombosis in COVID-19 patients $[7,8]$ and histologic analysis of pulmonary vessels in patients with COVID-19 showed widespread thrombosis with microangiopathy. Several pathological pathways are thought to be involved in microthrombi formation including endothelial damage, thrombin activation, platelet activation, neutrophil extracellular traps (NETs) formation, and contact pathway activation [9]. It is important to note the autopsy series of the some COVID-19 patients revealed diffusely edematous lung parenchyma and the presence of small and firm thrombi in sections of the peripheral lung, while pulmonary arteries at the hilum were free of thromboembolism and there were no signs of gross inflammation [10]. These findings demonstrate that while some of mechanisms can lead to both micro- and macrothrombotic complications (notably endothelium damage) pulmonary thrombosis is not accompanied by DVT and in many cases resulted from microthrombi formation in lung capillaries and small vessels with the absence of pulmonary thromboembolism. Some authors suggest that profound decline and alteration of pericytes (spatially isolated contractile cells present at intervals along the walls of capillaries and post-capillary venules) caused by a direct effect of SARS-CoV- 2 could be the initial trigger of the micro-vasculopathy [11].

In our series all COVID-19 patients with DVT had various degree of lung involvement detected by $\mathrm{CT}$ ranged from ground-glass opacities to consolidation patterns and CT did not detect any signs of pulmonary embolism (we did not perform lung biopsy). This indicated that DVT often do not led to thromboembolism, and remain "sleeping thrombi" without clinical manifestations. However, taking into account the resistance of COVID-19 induced thrombi to anticoagulant therapy they may led to complications in the future.

The D-dimer and C-reactive protein levels were increased in the majority of COVID-19 patients which is consistent with published data [12]. However, this increase was more pronounced in patients with DVT and, based on our observations; we proposed a D-dimer level threshold of $0.69 \mathrm{mcg} /$ $\mathrm{mL}$ as a level representing significantly increased risk of DVT. Based on study results, it is advisable to start anticoagulation therapy as early as possible in patients with moderate COVID-19 and continue it after discharge from hospital. Also, it perhaps makes sense to follow these patients and, at 
some point in the future, to perform venous ultrasonography to rule out DVT.

Acknowledgments Boris Kerbikov provided valuable input and feedback on the manuscript.

Author contributions $\mathrm{OK}, \mathrm{PO}$ and EB had full access to all of the data in the study and take responsibility for the integrity of the data and the accuracy of the data analysis. Concept and design: OK, PO, NN. Acquisition, analysis, or interpretation of data: OK, EB, PO. Drafting of the manuscript: OK.

\section{Compliance with ethical standards}

Conflict of interest There is no potential conflict of interest for each author.

\section{References}

1. Wichmann D, Sperhake JP, Lütgehetmann M, Steurer S, Edler C, Heinemann A, et al. Autopsy findings and venous thromboembolism in patients with COVID-19: a prospective cohort study. Ann Intern Med. 2020;173(4):268-77.

2. Nahum J, Morichau-Beauchant T, Daviaud F, Echegut P, Fichet J, Maillet JM, et al. Venous Thrombosis Among Critically Ill Patients With Coronavirus Disease 2019 (COVID-19). JAMA Netw Open. 2020; 3:5.

3. Klok FA, Kruip MJHA, van der Meer NJM, et al. Incidence of thrombotic complications in critically ill ICU patients with COVID-19. Thromb Res. 2020;191:148-50.

4. Huang G, Gong T, Wang G, Wang J, Guo X, Cai E, et al. Timely diagnosis and treatment shortens the time to resolution of coronavirus disease (COVID-19) pneumonia and lowers the highest and last CT scores from sequential chest CT. AJR Am J Roentgenol. 2020;30:1-7.

5. Thachil J, Tang N, Gando S, Falanga A, Cattaneo M, Levi M, et al. ISTH interim guidance on recognition and management of coagulopathy in COVID-19. J Thromb Haemost. 2020;18(5):1023-6.

6. McFadyen JD, Stevens H, Peter K. The emerging threat of (Micro) thrombosis in COVID-19 and its therapeutic implications. Circ Res. 2020;127(4):571-87.

7. Dolhnikoff M, Duarte-Neto AN, de Almeida Monteiro RA, da Silva LFF, de Oliveira EP, Saldiva PHN, et al. Pathological evidence of pulmonary thrombotic phenomena in severe COVID-19. J Thromb Haemost. 2020;18(6):1517-9.

8. Ackermann M, Verleden SE, Kuehnel M, Haverich A, Welte T, Laenger F, et al. Pulmonary vascular endothelialitis, thrombosis, and angiogenesis in Covid-19. N Engl J Med. 2020;383(2):120-8.

9. Mitchell WB. Thromboinflammation in COVID-19 acute lung injury. Paediatr Respir Rev. 2020;35:20-4.

10. Fox SE, Akmatbekov A, Harbert JL, Li G, Quincy Brown J, Vander et al. Pulmonary and cardiac pathology in African American patients with COVID-19: an autopsy series from New Orleans. Lancet Respir Med. 2020;8(7):681-6.

11. Cardot-Leccia N, Hubiche T, Dellamonica J, Burel-Vandenbos F, Passeron T. Pericyte alteration sheds light on micro-vasculopathy in COVID-19 infection. Intensive Care Med. 2020;46(9):1777-8.

12. Tang N, Li D, Wang X, Sun Z. Abnormal coagulation parameters are associated with poor prognosis in patients with novel coronavirus pneumonia. J Thromb Haemost. 2020;18(4):844-7.

Publisher's Note Springer Nature remains neutral with regard to jurisdictional claims in published maps and institutional affiliations. 